\title{
Cyanine dyes in solid state organic heterojunction solar cells
}

Jakob Heier, Chuyao Peng, Anna C. Véron, Roland Hany, Thomas Geiger, et al.

Jakob Heier, Chuyao Peng, Anna C. Véron, Roland Hany, Thomas Geiger, Frank A. Nüesch, Marcus V. G. Vismara, Carlos F. O. Graeff, "Cyanine dyes in solid state organic heterojunction solar cells," Proc. SPIE 9184, Organic Photovoltaics XV, 918408 (6 October 2014); doi: 10.1117/12.2063977

SPIE Event: SPIE Organic Photonics + Electronics, 2014, San Diego, California, United States 


\title{
Cyanine dyes in solid state organic heterojunction solar cells
}

\author{
Jakob Heier*a , Chuyao Peng ${ }^{\mathrm{a}}$, Anna C. Véron ${ }^{\mathrm{a}}$, Roland Hany ${ }^{\mathrm{a}}$, Thomas Geiger ${ }^{\mathrm{a}}$, Frank A. Nüesch ${ }^{\mathrm{a}}$, Marcus V. G. \\ Vismara $^{\mathrm{b}}$, Carlos F.O. Graeff ${ }^{\mathrm{b}}$ \\ ${ }^{a}$ EMPA, Swiss Federal Laboratories for Materials Science and Technology, Laboratory for Functional Polymers, \\ Ueberlandstrasse 129, 8600 Dübendorf, Switzerland;

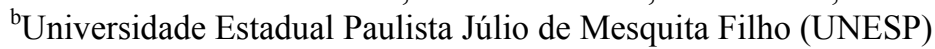 \\ 17033-360 - Bauru, SP, Brasil
}

\begin{abstract}
Today numerous cyanine dyes that are soluble in organic solvents are available, driven by more than a century of research and development of the photographic industry. Several properties specific to cyanine dyes suggest that this material class can be of interest for organic solar cell applications. The main absorption wavelength can be tuned from the ultra-violet to the near-infrared. The unparalleled high absorption coefficients allow using very thin films for harvesting the solar photons. Furthermore, cyanines are cationic polymethine dyes, offering the possibility to modify the materials by defining the counteranion. We here show specifically how counterions can be utilized to tune the bulk morphology when blended with fullerenes. We compare the performance of bilayer heterojunction and bulk heterojunction solar cells for two different dyes absorbing in the visible and the nearinfrared. Light-induced Electron Spin Resonance (LESR) was used to study the charge transfers of light induced excitons between cyanine dyes and the archetype fullerene $\mathrm{C}_{60}$. LESR results show good correlation with the cell performance.
\end{abstract}

Keywords: Organic solar cells, Cyanine dyes, PCBM, C60, Bulk heterojunction, Counterion, Solvent quench, Light-induced electron spin resonance

\section{INTRODUCTION}

For applications in solar energy harvesting, polymethine dyes have been found to show useful properties in dye sensitized solar cells (DSSCs) ${ }^{1}$ as well as in solid state organic thin film solar cells. ${ }^{2}$ Appealing are their tunable absorption wavelength $\left(\lambda_{\max }\right)$ and high molar extinction coefficients $\left(\varepsilon>10^{5} \mathrm{M}^{-1} \mathrm{~cm}^{-1}\right)$. Tunable absorption allows e.g. for the fabrication of transparent solar cells. ${ }^{3,4}$ The high molar extinction coefficient allows for the fabrication of efficient bi-layer solar cells. ${ }^{5}$ By using common counterions such as $\mathrm{ClO}_{4}^{-}$or $\mathrm{PF}_{6}^{-}$, blending the dye with PCBM does not lead to a fine scale phase separated bulk heterojunction (BHJ) morphology but to large scale phase separation ${ }^{6}$ lethal to solar cell performance. ${ }^{7}$ In general, efficient devices show phase separated structures in the range of the exciton diffusion length $(5-20 \mathrm{~nm}$ ) which preferentially possess continuous pathways in both phases to guarantee loss-free charge transport to the respective electrodes. ${ }^{8}$ Preferentially, such a favorable phase morphology establishes during spin-coating: phase separation sets in through a solvent quench, the established phase structure is quickly immobilized upon further solvent removal. ${ }^{9}$ Fine tuning of morphology and cell performance can be improved by various treatments such as thermal annealing, solvent annealing and the use of solvent additives. ${ }^{10}$ Another method to control, minimize and stabilize phase structures is the use of electrostatic phenomena. It could be shown both theoretically and experimentally that incorporating small fractions of charges in one polymer chain can effectively enhance the polymer-polymer compatibility. ${ }^{11}$ The mechanism for that can be understood as follows: during the coating process, the solvent evaporates and solute - solute interactions start to dominate (solvent quench). ${ }^{9}$ In a ternary system (compound 1 - compound 2 - solvent) for example, unfavorable interactions between two different solutes may lead to phase separation. This is generally true for polymer blends where the entropic contribution to the free energy of mixing is small, ${ }^{12}$ blends of small molecules with large enough repulsive interactions also phase separate. In polyelectrolyte - polymer systems a dissociated counterion will greatly contribute to the entropy of mixing and thus disfavors phase separation. ${ }^{11}$ Comparable studies with blend systems of small molecules are missing. E.g. in cyanine dyes, depending on counterion and 
solvent, tight and solvent separated ion pairs are assumed to equilibrate with free solvated ions. ${ }^{13}$ Bouit et al. for example studied the influence of the counterions on the optical properties of cyanine dyes. ${ }^{14}$ To the best of our knowledge, no studies are available that demonstrate the concept to tune the phase behavior of the dyes in a blend system for photovoltaic applications via electrostatic interactions. Light-induced electron spin resonance (LESR) studies on conjugated polymer/fullerene composites have been reported. ${ }^{15,16}$ Two signals were observed, one attributed to positive polarons on the polymer chain and the other to radical anions on the fullerene molecule. In this paper we show that cyanine dyes with two different counterions show very different blend morphologies, we compare the performance of BHJs of two dyes with different counterions to their performance in bilayer cells. Using LESR we show further that the counterion affects the charge transfer and transport close to the dye $/ \mathrm{C}_{60}$ interface.

\section{EXPERIMENTAL}

Heptamethine dyes with the counterion $\mathrm{PF}_{6}^{-}(\mathrm{Cy} 7-\mathrm{P})$ and TRISPHATE ${ }^{-}$(Cy7-T) were synthesized following a procedure reported earlier. ${ }^{4}$ Trimethine dyes (Cy3-P and Cy3-T) were synthesized following similar procedures. The compounds are shown in Figure 1. Solar cells were manufactured from all four dyes in two different active layer configurations. In bilayer cells, a $40 \mathrm{~nm}$ thick $\mathrm{C}_{60}$ (purchased from SES research) layer was thermally evaporated on top of a $20 \mathrm{~nm}$ thick dye layer that was spin coated from chlorobenzene or tetrafluoropropanol (TFP) solutions. For bulk heterojunction solar cells, the cyanine dyes were blended with the fullerene derivate PCBM (Solenne B.V.) in chlorobenzene and spincoated onto the substrates. The active layers were coated onto ITO coated glass (Thin Film Devices, Inc.) covered by a $30 \mathrm{~nm}$ thick $\mathrm{MoO}_{3}$ (Sigma Aldrich) layer deposited by thermal evaporation. The cathode layer consisted of a $2 \mathrm{~nm}$ thick Alq 3 layer (Sigma Aldrich, 99.995\%) followed by a $60 \mathrm{~nm}$ thick silver layer (Cerac, $99.99 \%$ ). Silver was evaporated through a shadow mask to define solar cell areas. Solvents for solar cell fabrication were purchased from Aldrich (synthetic grade) and used without further purification. All cells were manufactured inside a nitrogen filled glove box $\left(<1 \mathrm{ppm}_{2} \mathrm{O},<6 \mathrm{ppm} \mathrm{O}_{2}\right)$. Materials were sublimed under vacuum at a pressure of $5 \times 10^{-6} \mathrm{mbar}$. Solar cells were characterized with a calibrated $100 \mathrm{~mW} \mathrm{~cm}{ }^{-2}$ AMG1.5 class A solar simulator from Spectra Nova. The efficiency values have not been corrected for an eventual spectral mismatch due to characteristic lamp emission peaks in the absorption range of the dyes, but short circuit current measurements were performed outdoors and compared to measurements with the solar simulator. The values were found to deviate maximally by $10 \%$.

Atomic force microscopy (AFM) images were taken with a Nanosurf Mobile S (Nanosurf AG). UV-Vis spectra were taken with a Varian Cary 50. For the LESR measurements a Miniscope MS300 spectrometer, from Magnettech (X-band and 9.3 - $9.55 \mathrm{GHz}$ ) was used. The microwave power was applied between $0.100 \mathrm{~mW}$ and $31.62 \mathrm{~mW}$. Samples were illuminated by a $140 \mathrm{~W}$ xenon lamp from a Newport solar simulator using an AM 1.5 filter. The illumination was applied inside the ESR cavity. The temperature was varied between $77 \mathrm{~K}$ and $298 \mathrm{~K}$. The blends were made using 1:1 wt $\%$ of dye and the archetype fullerene $\mathrm{C}_{60}$ in chlorobenzene. Films were casted onto glass substrate; the films were scraped off the substrate and placed inside the ESR tubes. Diphenylpicrylhydrazyl (DPPH) with $\mathrm{g}=2.0036$ was used as reference to determine the $\mathrm{g}$ factor. The spin density was determined by comparison with an amorphous silicon sample with known spin concentration. ${ }^{17}$ Modulation amplitude and microwave power were set in order to avoid signal saturation and distortion. Computer simulations were performed using the software EasySpin (http://www.easyspin.org/). 

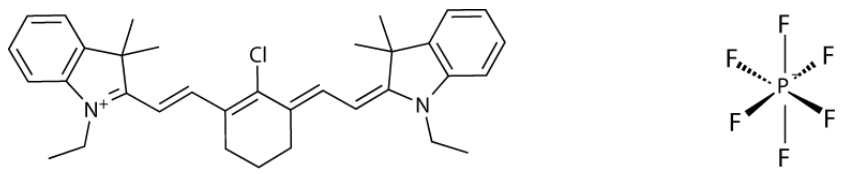

$\mathrm{Cy} 7^{+}$

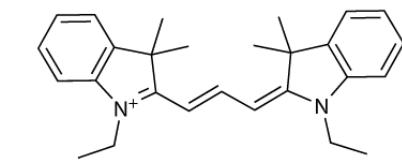

$\mathrm{Cy} 3^{+}$
$\mathrm{PF}_{6}^{-}$<smiles></smiles>

Figure 1. Structure of the heptamethine $(\mathrm{Cy} 7+)$ and trimethine $(\mathrm{Cy} 3+)$ cations (left) and the $\mathrm{PF}^{-}$and TRISPHATE ${ }^{-}$counterions (right).

\section{RESULTS}

In Figure 2a we compare I-V-curves of bilayer cells fabricated from the four different dyes. The manufacturing recipe is adapted from optimized manufacturing procedures reported elsewhere. ${ }^{5}$ We observe distinct differences that seem to be characteristic to the individual dyes. To be more specific: besides Cy3-T, all devices show rectifying behavior, compared to the trimethine dyes, the heptamethine dyes have a smaller $\mathrm{V}_{\mathrm{oc}}$, but larger $\mathrm{I}_{\mathrm{sc}}$. In Figure $2 \mathrm{~b}$ we show the I-V curves of the four dyes in solar cells when blended with PCBM. All devices show rectification, but a strongly voltage dependent reverse current, indicative for problems with charge extraction (or selectivity of contacts). The performance parameters of all cells are summarized in Table 1 . The trends in the characteristics of the I-V-curves for each dye/counterion pair though are similar in the blend sample and in the bilayer sample. This indicates the importance of the material as such, but it also suggests that the different dyes show a similar phase separation behavior when blended with PCBM. Surprisingly, that is not the case.
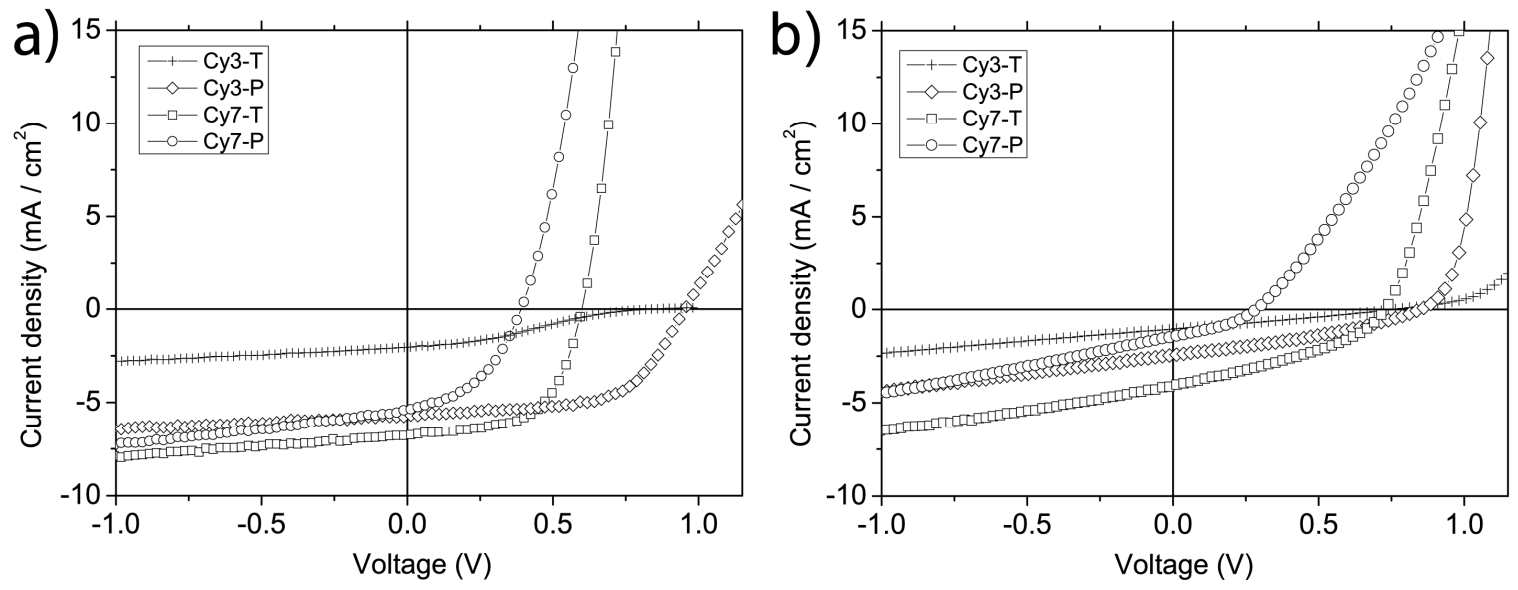

Figure 2. I-V curves under illumination of all dyes in a bilayer geometry with $\mathrm{C}_{60}$ as electron acceptor (a) and when blended with PCBM (b). 
Table 1: Summary of the best efficiencies of the solar cells under investigation.

\begin{tabular}{|l|l|l|}
\hline PCE (\%) & BHJ & Bilayer \\
\hline Cy3-P & 0.69 & $3.5^{18}$ \\
\hline Cy3-T & 0.22 & 0.67 \\
\hline Cy7-P & 0.15 & $1.5^{3}$ \\
\hline Cy7-T & 1.09 & $2.2^{4}$ \\
\hline
\end{tabular}

In the following we show that the dye with the counterion $\mathrm{PF}_{6}{ }^{-}$leads to completely different phase morphologies when blended with PCBM compared to a dye with the counterion TRISPHATE. AFM scans reveal that the two dyes with the $\mathrm{PF}_{6}{ }^{-}$counterion evolve into a bilayer with a relatively rough interfacial layer during solvent evaporation (dye at the substrate, PCBM at the air interface). With the solvent hexane we can selectively dissolve the top PCBM layer from the samples, revealing the bilayer character of the film (Figure 3). What hampers the device performance for these samples are dewetting holes in the entire film. Fluorescence experiments show that neither PCBM fluorescence nor dye fluorescence is fully quenched, again confirming full phase separation.

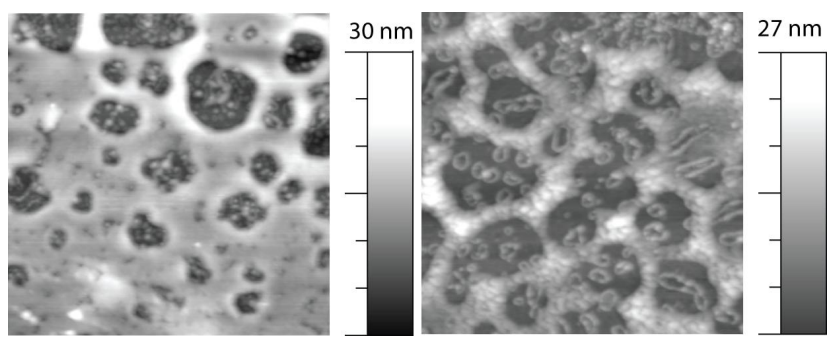

Figure 3. AFM images of a Cy7-P sample blended with PCBM. The left image shows the film as spin-coated, the right image shows the sample after dissolving PCBM from the film. The width of the images is $4 \mu \mathrm{m}$.

Differently, the films with the TRISPHATE counterion are initially flat. With TFP we find a selective solvent for the dye. Monitoring the dissolution speed (from UV-Vis spectroscopy, Figure 4) gives a first idea of the film morphology. In a first stage a surface segregation layer of dye can quickly be removed with TFP $(0<\mathrm{t}<40$ min). In a second stage, dye and PCBM are simultaneously removed from the sample at a much lower dissolution speed than for plain dye but much faster than for PCBM. This suggests that the bulk of the sample is a blend phase of dye and PCBM. This hypothesis is supported by fluorescence measurements, both, dye and PCBM emission is fully quenched. 


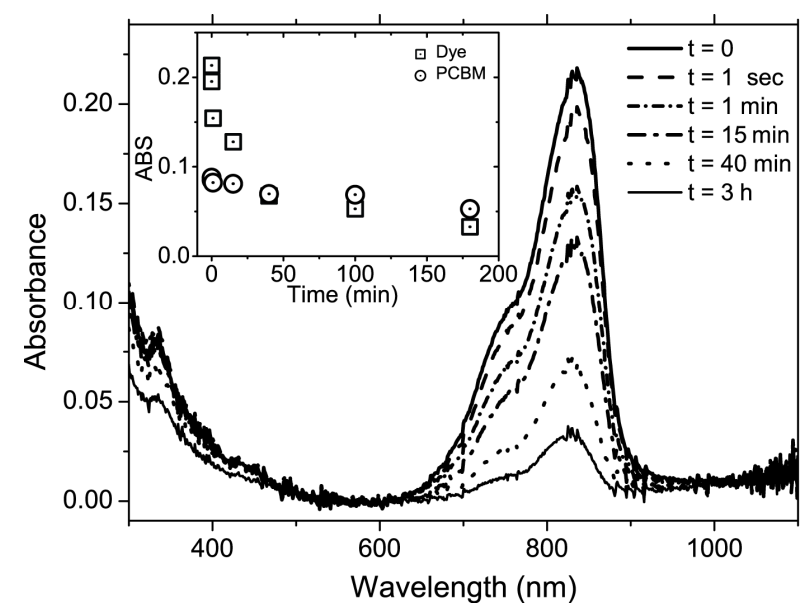

Figure 4. UV-Vis spectra of a Cy7-T film blended with PCBM during rinsing with TFP.

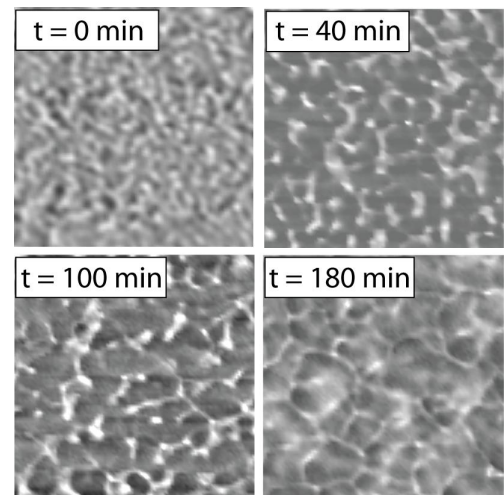

Figure 5. AFM phase images of Cy7-T samples after rinsing with TFP for $\mathrm{t}=0 \mathrm{~min}, 40 \mathrm{~min}, 100 \mathrm{~min}$ and 180 min. Longer rinsing times correspond to a section of the film closer to the substrate and thus to a section that solidified earlier. The width of the images is $1.2 \mu \mathrm{m}$.

AFM phase images of the sample surface can give interesting insights in the phase separation process (Figure 5). When entering the miscibility gap during the solvent quench, composition fluctuations occur on the length of the spinodal wavelength. That wavelength depends e.g. on the depth of the quench. The phase images taken at different sections of the sample show a clear contrast between a PCBM-rich and a dye-rich phase and can be identified as a spinodal wavelength at the moment when the phase solidifies. The lateral dimensions of the features grow with rinsing time and proof the dynamic character of the phase separation process. The images will be interpreted in the discussion section.

LESR measurements were performed on heptamethine dyes blended with $\mathrm{C}_{60}$ in order to complement the characterization in the nanoscale level of the interface between the two molecules dye/ $\mathrm{C}_{60}$. We assume a similar blending behavior of the dyes with PCBM and $\mathrm{C}_{60}$. LESR is sensitive only to the charges (spins) that were transferred from one molecule to other. $\mathrm{C}_{60}$ showed a single (L)ESR signal with $\mathrm{g}$ factor of 1.999 in agreement with the literature. ${ }^{15}$ For the pristine dyes no (L)ESR signals were observed. For the blends three LESR signals were observed with a $\mathrm{g}$ factor of $1.9989,2.0019$ and 2.0025 , with linewidths of $2.5 \mathrm{G}, 2.5 \mathrm{G}$ and $20 \mathrm{G}$ respectively for Cy7-P/ $\mathrm{C}_{60}$ and $4.6 \mathrm{G}, 4.3 \mathrm{G}$ and $20 \mathrm{G}$ for $\mathrm{Cy} 7-\mathrm{T} / \mathrm{C}_{60}$. Figure 6 shows the LESR spectrum and its simulation for the $\mathrm{Cy} 7-\mathrm{P} / \mathrm{C}_{60}$ blend. The signals with $\mathrm{g}$ factor at 2.0019 and 2.0025 are assigned to the dye. 


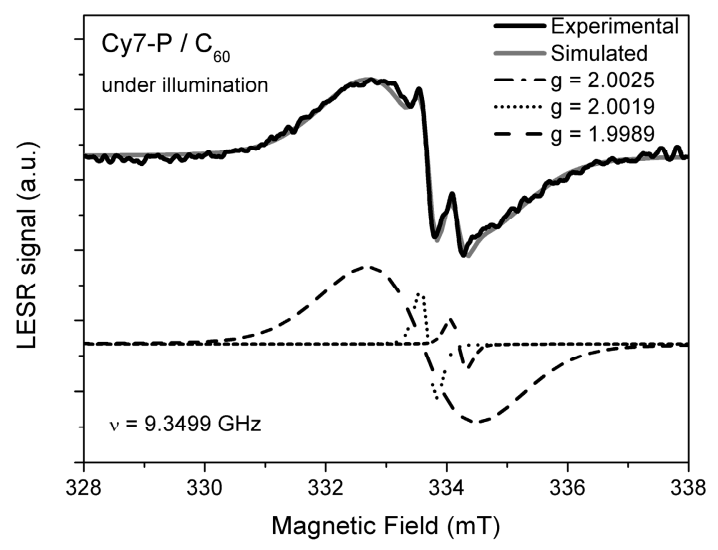

Figure 6. LESR of $\mathrm{Cy} 7-\mathrm{P} / \mathrm{C}_{60}$ at $77 \mathrm{~K}$. The black line is the experimental signal, the gray line the simulated. The components of the simulated signal are presented as dash-dotted, dotted and dashed lines.

Figure 7 shows the (L)ESR signals for $\mathrm{Cy} 7-\mathrm{P} / \mathrm{C}_{60}$ and $\mathrm{Cy} 7-\mathrm{T} / \mathrm{C}_{60}$ blends with and without illumination. An increase in the intensity of the ESR signal is related to the light induced charge generation and transfer between the cyanine dye and $\mathrm{C}_{60}$. $\mathrm{Cy} 7-\mathrm{T} / \mathrm{C}_{60}$ shows a significant increase in the $\mathrm{C}_{60}$ signal compared to the dye. The spin densities in the dark and under illumination for each component of the (L)ESR signals are shown in Table 2. For the signal at $\mathrm{g}=2.0025$ from $\mathrm{Cy} 7-\mathrm{P} / \mathrm{C}_{60}$ under illumination the spin-density increase two times while for Cy7$\mathrm{T} / \mathrm{C}_{60}$ six times. For the signal at $\mathrm{g}=2.0019$ for both samples, illumination does not promote a significant increase in the spin-density. For the $\mathrm{g}=1.9989$ signal, there is a spin-density increase under illumination of seven times for $\mathrm{Cy} 7-\mathrm{P} / \mathrm{C}_{60}$ and one hundred and twenty times for $\mathrm{Cy} 7-\mathrm{T} / \mathrm{C}_{60}$.
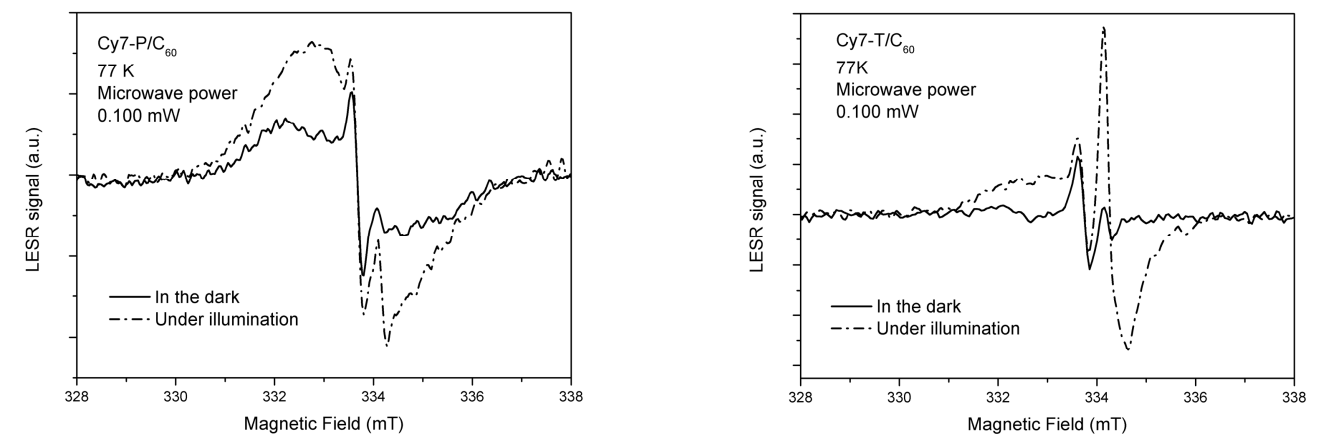

Figure 7. ESR (solid line) and LESR (dotted line) signals for $\mathrm{Cy} 7-\mathrm{P} / \mathrm{C}_{60}$ and $\mathrm{Cy} 7-\mathrm{T} / \mathrm{C}_{60}$ blends.

Table 2: Spin-density from the different components of the (L)ESR signals obtained from the best fits for the different samples.

\begin{tabular}{|c|c|c|c|c|c|c|}
\hline \multirow[t]{2}{*}{$\mathrm{g}$ factor } & \multicolumn{2}{|c|}{$\begin{array}{c}\mathrm{Cy} 7-\mathrm{P} / \mathrm{C}_{60} \\
\text { (spins/g) }\end{array}$} & \multicolumn{2}{|c|}{$\begin{array}{c}\mathrm{Cy} 7-\mathrm{T} / \mathrm{C}_{60} \\
\text { (spins/g) }\end{array}$} & \multicolumn{2}{|c|}{$\begin{array}{l}\mathrm{Cy} 7-\mathrm{I} / \mathrm{C}_{60} \\
\text { (spins/g) }\end{array}$} \\
\hline & In the dark & Illuminated & In the dark & Illuminated & In the dark & Illuminated \\
\hline 2.0025 & $1.7 \times 10^{17}$ & $3.6 \times 10^{17}$ & $6.1 \times 10^{16}$ & $3.9 \times 10^{17}$ & --- & ---- \\
\hline 2.0019 & $4.2 \times 10^{15}$ & $6.2 \times 10^{15}$ & $1.1 \times 10^{16}$ & $1.3 \times 10^{16}$ & $3.5 \times 10^{15}$ & $2.7 \times 10^{15}$ \\
\hline 1.9989 & $4.1 \times 10^{14}$ & $2.8 \times 10^{15}$ & $1.4 \times 10^{15}$ & $1.7 \times 10^{17}$ & $4.5 \times 10^{14}$ & $2 \times 10^{16}$ \\
\hline
\end{tabular}


The microwave power dependence of the different LESR components from the $\mathrm{Cy} 7-\mathrm{P} / \mathrm{C}_{60}$ blend is presented in Figure 8. For $\mathrm{Cy} 7-\mathrm{T} / \mathrm{C}_{60}$ a similar behavior is observed. For the component with $\mathrm{g}=2.0025$ saturation is observed (inhomogeneous broadening). The component with $\mathrm{g}=2.0019$ is in the saturation regime for all microwave power used. On the other hand the signal related to $\mathrm{C}_{60}$, does not enter the saturation regime.

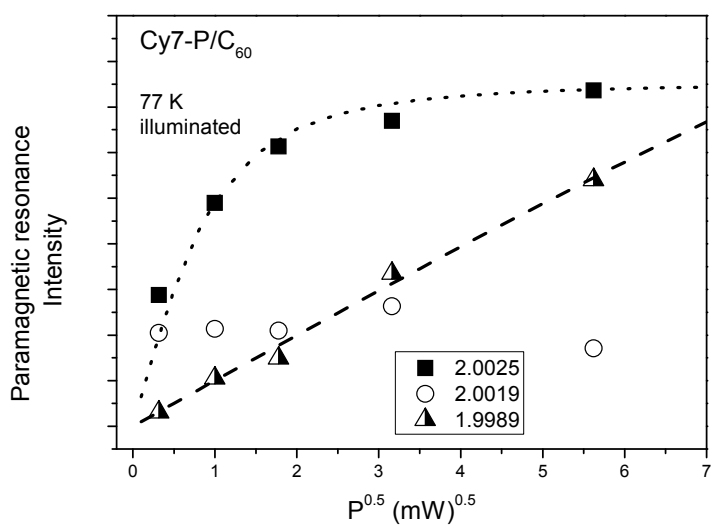

Figure 8. Microwave absorption amplitude dependence on microwave power for $\mathrm{Cy} 7-\mathrm{P} / \mathrm{C}_{60}$. The lines show calculated dependences.

From the behavior observed it is possible to estimate the spin-lattice relaxation time $T_{1}$ for the component with $\mathrm{g}=2.0025$, approximately $10^{-7} \mathrm{~s}$. In this estimation one is assuming that the spin-spin relaxation time $\left(\mathrm{T}_{2}\right)$ is dominated by $\mathrm{T}_{1}$. For the component with $\mathrm{g}=2.0019$ one expects a longer relaxation time, while the $\mathrm{C}_{60}$ component has a shorter $\mathrm{T}_{1}$ compared to the $\mathrm{g}=2.0025$ component.

\section{DISCUSSION}

The behavior of our system suggests that the phase morphology is greatly determined by the difference in dissociation behavior of the two counterions. Chlorobenzene with a dielectric constant of $\varepsilon_{\mathrm{r}}=5.62$ can be considered to be a weakly monopolar solvent. As a consequence, the smaller counterion $\mathrm{PF}_{6}{ }^{-}$may show a higher tendency to remain associated even in diluted solutions. An associated counterion favors phase separation. On the other side, the larger bulky counterion TRISPHATE ${ }^{-}$will partially dissociate, leading to a disfavor of separated phases. 


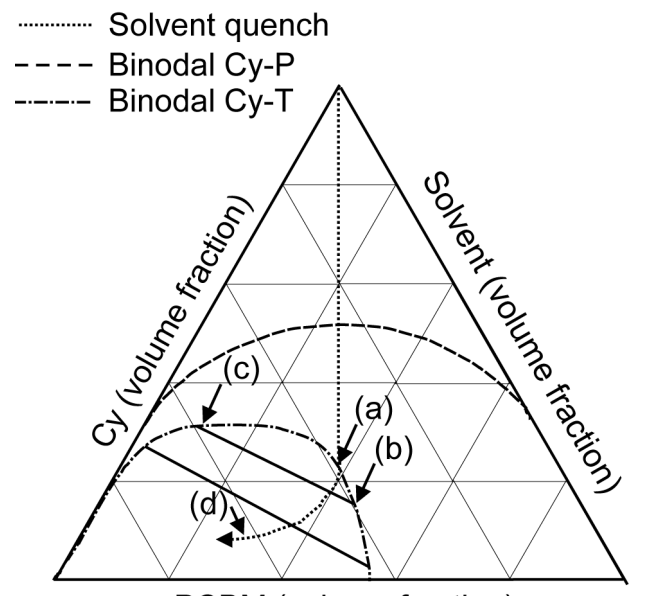

PCBM (volume fraction)

Figure 9. Ternary phase diagram illustrating the morphology evolution during solvent quench for dye/PCBM blends.

With the help of a ternary phase diagram we can explain the evolution of the morphology (Figure 9). For the dyes with the counterion $\mathrm{PF}_{6}{ }_{6}$, lower tendency to counterion dissociation leads to a large miscibility gap. Upon solvent evaporation, the system quickly separates into pure PCBM and dye phases. The situation is more complicated for the dyes with a TRISPHATE- counterion. The higher tendency to counterion dissociation leads to a smaller miscibility gap. From the dissolution studies we must state that the gap is not symmetric with composition. Given the electrolytic character of the dye we can argue that upon phase separation, the dye rich phase is less concentrated. In the phase diagram that is reflected in tie-lines not parallel to the PCBM volume fraction axis. Film formation now proceeds as follows: as solvent evaporates, the system will cross the binodal and enter the immiscibility region (a). Inside the gap, the system separates into a dye rich phase and a PCBM rich phase. The PCBM rich phase is more concentrated and will solidify first with a composition given by the binodal (b). At this time the system is still very close to the binodal, correspondingly large is the spinodal wavelength as seen in Figure 5 ( $\mathrm{t}=180 \mathrm{~min})$. The dye phase is less concentrated and will remain liquid (c). As a PCBM rich phase solidifies first, the fraction of dye in the remaining liquid increases (d). At the same time, the depth of the quench increases, decreasing the spinodal wavelength (Figure 5, $\mathrm{t}=100 \mathrm{~min}$ and $\mathrm{t}=40 \mathrm{~min}$ ). At the end of the process, a liquid dye layer solidifies, this is the surface dye layer that can be removed first by TFP (Figure 5, $\mathrm{t}=0 \mathrm{~min}$ ). A quantitatively similar behavior is observed with the trimethine dyes.

In the LESR experiments, to understand the nature of the dye related signals we have included data from another counter ion (iodine) see Table 2. For Cy7-I/ $\mathrm{C}_{60}$ the $\mathrm{C}_{60}$ component has a $\mathrm{g}$ factor of 1.9989 and linewidth around $2.5 \mathrm{G}$. The dye related component has a $\mathrm{g}$ factor at 2.0021 with a linewidth around $2.5 \mathrm{G}$. Important to notice is that the broad signal around 2.0025 is not observed. Similarly to the other counter ions the $\mathrm{C}_{60}$ component has a large increase in spin-density on illumination $(\times 44)$ while the signal at 2.0021 has no significant change in intensity. Thus for the $\mathrm{g}=2.0019(21)$ it is believed that it is related to defects. This explains the saturation behavior (Figure 8), these spins have long relaxation times compatible with an energetically deep state. No increase in the spin-density after illumination is observed suggesting that these spins do not participate in the photogenerated charge transfer process. The density of spins study shows that $\mathrm{Cy} 7-\mathrm{P} / \mathrm{C}_{60}$ blend has a smaller number of defects than $\mathrm{Cy} 7-\mathrm{T} / \mathrm{C}_{60}$. For $\mathrm{Cy} 7-\mathrm{I} / \mathrm{C}_{60}$ the absence of the broad signal $(\mathrm{g}=2.0025)$ may be related to the fact that $\mathrm{I}^{-}$ counterion is very reactive, causing either the quick relaxation of the positive polaron after charge transfer to the dye; or to a decrease in its $T_{1}$. More work is underway to understand this effect.

Analysing the spin-density changes indicate that the charge transfer is more effective in Cy7-T/ $\mathrm{C}_{60}$. On the other hand in a first approximation one should expect a balanced increase of $\mathrm{C}_{60}$ and Cy7-T(P) related signals, since for each exciton one charge is generated in the $\mathrm{C}_{60}$ and $\mathrm{Cy} 7-\mathrm{T}(\mathrm{P})$ after the transfer. This is specially not true in 
the Cy7-P/ $\mathrm{C}_{60}$. This imbalance in the number of spins of dye and $\mathrm{C}_{60}$ may be related to the formation of $\mathrm{C}_{60}$ aggregates which would increase the probability of the negative polaron to diffuse more easily to a recombination center.

The LESR results are in agreement with PCE, where better efficiencies are observed in $\mathrm{Cy} 7-\mathrm{T} / \mathrm{C}_{60}$ compared to Cy7-P/C 60 . As the LESR signal with g-factor in 2.0019 is possibly related to the defects, it was expected that the blend of $\mathrm{Cy} 7-\mathrm{P} / \mathrm{C}_{60}$, that have fewer number of these defects, present a higher PCE that for Cy7-T/ 60 . However this defect apparently is electrically inactive, thereby not influencing the charge generation and transfer process.

\section{CONCLUSIONS}

We demonstrated the blending behavior between PCBM and four cyanine dyes with two different counterions. The dyes are known to perform reasonably well in a bi-layer configuration. In the blend, the phase morphology is efficiently controlled by electrostatic interactions via the counterion, as seen in morphological differences between $\mathrm{PF}_{6}^{-}$and TRISPHATE- The dyes with a $\mathrm{PF}_{6}^{-}$counterion form ruptured (dewetting) bilayers of separated phases of plain dye and phases of plain PCBM. In films that form with dyes with the TRISPHATE ${ }^{-}$counterion also two phases develop, but at least the PCBM rich phase contains a large fraction of dye. In this phase dye and PCBM in equilibrium are practically intermixed. Obviously, both morphologies are non-ideal for good solar cell efficiencies. But, with the choice of the counterions $\mathrm{PF}_{6}^{-}$and TRISPHATE ${ }^{-}$we cover two extreme thin film morphologies. We expect an improved behavior for films where the interaction parameters for phase separation are between the dye with $\mathrm{PF}_{6}^{-}$and TRISPHATE${ }^{-}$counterions. The experiments also show that the performance of a specific dye in a planar bilayer heterojunction determines to a large extend the I-V-curves in the bulk heterojunction, fully independent of the morphology in the bulk.

LESR results showed that the blend of $\mathrm{Cy} 7-\mathrm{P} / \mathrm{C}_{60}$ has a lower generation of spins and charge transfer as compared to the blend of Cy7-T/ $\mathrm{C}_{60}$. This is due to the fact that the Cy7-P dye and $\mathrm{C}_{60}$ phase segregate, thereby reducing the interaction between the compounds and thus lowering charge transfer from Cy7-P to $\mathrm{C}_{60}$. On the other hand, a Cy7-T/ $\mathrm{C}_{60}$ blend forms intermixed phases making a more effective charge transfer possible, which is evidenced by a greater number in spin density after illumination of the samples. A component tentatively assigned to a deep defect is identified.

*Jakob.Heier@empa.ch; phone 004158765 4356; fax 0041587651122

\section{ACKNOWLEDGMENTS}

This project was supported by the Brazilian Swiss Joint Research Program (BSJRP). The authors do also acknowledge the Brazilian Agency FAPESP under contracts 2013/07296-2 and 2008/57872-1, as well as CNPq contract 573636/2008-7,

\section{REFERENCES}

[1] Geiger, T., Schoger, I., Rentsch, D., Veron, A. C., Oswald, F., Meyer, T. and Nüesch, F., "Unsymmetrical Heptamethine Dyes for NIR Dye-Sensitized Solar Cells," International Journal of Photoenergy Article ID 258984 (2014). 
[2] Fan, B., de Castro, F. A., Chu, B. T. T., Heier, J., Opris, D., Hany, R. and Nuesch, F., "Improved performance of cyanine solar cells with polyaniline anodes," Journal of Materials Chemistry 20, 2952-2955 (2010).

[3] Zhang, H., Wicht, G., Gretner, C., Nagel, M., Nüesch, F., Romanyuk, Y., Tisserant, J.-N. and Hany, R., "Semitransparent organic photovoltaics using a near-infrared absorbing cyanine dye," Solar Energy Materials \& Solar Cells 118, 157-164 (2013).

[4] Veron, A. C., Zhang, H., Linden, A., Nuesch, F., Heier, J., Hany, R. and Geiger, T., "NIR-Absorbing Heptamethine Dyes with Tailor-Made Counterions for Application in Light to Energy Conversion," Organic Letters 16, 1044-1047 (2014).

[5] Fan, B., Hany, R., Moser, J. E. and Nuesch, F., "Enhanced cyanine solar cell performance upon oxygen doping," Organic Electronics 9, 85-94 (2008).

[6] Heier, J., Groenewold, J., Huber, S., Nuesch, F. and Hany, R., "Nanoscale structuring of semiconducting molecular blend films in the presence of mobile counterions," Langmuir 24, 7316-7322 (2008).

[7] Heier, J., Groenewold, J., Castro, F. A., Nueesch, F. and Hany, R., "Enlarged bilayer interfaces from liquidliquid dewetting for photovoltaic applications," Proc. SPIE 6999, 1J1-1J9 (2008).

[8] Hoppe, H. and Sariciftci, N. S., "Morphology of polymer/fullerene bulk heterojunction solar cells," Journal of Materials Chemistry 16, 45-61 (2006).

[9] DalnokiVeress, K., Forrest, J. A., Stevens, J. R. and Dutcher, J. R., "Phase separation morphology of thin films of polystyrene/polyisoprene blends," Journal of Polymer Science Part B-Polymer Physics 34, 3017-3024 (1996).

[10] Peet, J., Kim, J. Y., Coates, N. E., Ma, W. L., Moses, D., Heeger, A. J. and Bazan, G. C., "Efficiency enhancement in low-bandgap polymer solar cells by processing with alkane dithiols," Nature Materials 6, 497500 (2007).

[11] Piculell, L. and Lindman, B., "Association and segregation in aqueous polymer/polymer, polymer surfactant, and surfactant surfactant mixtures - differences and similarities," Advances in Colloid and Interface Science 41, 149-178 (1992).

[12] Flory, P. J., "Thermodynamics of high polymer solutions," Journal of Chemical Physics 9, 660-661 (1941).

[13] Tatikolov, A. S., Ishchenko, A. A., Ghelli, S. and Ponterini, G., "Ion pairs of indobenzimidazolo cyanines: a structural study based on conductivity, absorption, fluorescence and H-1-NMR," Journal of Molecular Structure 471, 145-159 (1998).

[14] Bouit, P. A., Aronica, C., Toupet, L., Le Guennic, B., Andraud, C., Maury, O., "Continuous Symmetry Breaking Induced by Ion Pairing Effect in Heptamethine Cyanine Dyes: Beyond the Cyanine Limit," Journal of the American Chemical Society 132, 4328-4335 (2010).

[15] Krinichnyi, V. I. and Yudanova, E. I., "Structural effect of electron acceptor on charge transfer in poly(3hexylthiophene)/methanofullerene bulk heterojunctions," Solar Energy Materials and Solar Cells 95, 2302-2313 (2011).

[16] Zoriniants, G., Dyakonov, V., Scharber, M., Brabec, C. J., Janssen, R. A. J., Hummelen, J. C. and Sariciftci, N. S., "Light-induced ESR studies in conjugated polymer-fullerene composites," Synthetic Metals 102, 12411242 (1999).

[17] Poole, C. P., [Electron spin resonance : a comprehensive treatise on experimental techniques], John Wiley \& Sons: New York, 1983.

[18] Wicht, G., Bucheler, S., Dietrich, M., Jager, T., Nuesch, F., Offermans, T., Tisserant, J. N., Wang, L., Zhang, H. and Hany, R., "Stability of bilayer trimethine cyanine dye/fullerene organic solar cells," Solar Energy Materials and Solar Cells 117, 585-591 (2013). 